\title{
GARIS: UMA ANÁLISE DO FENÔMENO DA INVISIBILIDADE PÚBLICA EM PARALELO AO ENFRENTAMENTO DA PANDEMIA DO CORONAVÍRUS \\ (COVID-19)
}

\author{
SOLID WASTE COLLECTORS: AN ANALYSIS OF THE PHENOMENON OF \\ PUBLIC INVISIBILITY IN PARALLEL TO THE CORONAVIRUS PANDEMIC \\ (COVID-19)
}

\author{
Isabela Bruno de Almeida*
}

\begin{abstract}
RESUMO
No presente artigo investigam-se os efeitos da pandemia no âmbito do direito do trabalho; se, com a pandemia do coronavírus, as medidas de segurança impostas no meio ambiente de trabalho possuem aplicabilidade no ambiente de "labor" dos coletores de resíduos sólidos garis; se esses trabalhadores estariam sendo devidamente resguardados pelo meio jurídico e político-social brasileiro. Para tanto, foram utilizados, como metodologia de abordagem e de procedimento, o método dedutivo e o de estudo de caso. Dessa forma, o trabalho foi subdividido em três tópicos. No primeiro evidenciaram-se as principais medidas de prevenção, controle e mitigação da transmissão do vírus da covid-19, no segundo conceituou-se o meio ambiente de trabalho dos garis, e por fim foi analisada a aplicabilidade, ou não, das medidas protetivas de segurança inerentes à pandemia do coronavírus. Ao fim do estudo, conclui-se pelo descumprimento estatal de garantia e tutela de um dos direitos fundamentais do cidadão trabalhador: o de acesso à saúde ocupacional.
\end{abstract}

Palavras-chave: Pandemia coronavírus; garis; saúde ocupacional.

\begin{abstract}
This paper investigates the effects of the pandemic on work; if, with the coronavirus pandemic, the safety measures imposed in the work environment have applicability in the "work" environment of solid waste collectors - street sweepers; if these workers were being duly protected by the Brazilian legal and political-social environment. For this purpose, the deductive method and the case study method were used as approach and procedure methodology. Thus, the work was subdivided into three topics. The first highlighted the main measures to prevent, control and mitigate the transmission of the covid-19 virus, the second conceptualized the work environment of street sweepers, and finally, the applicability, or not, of the protective safety measures inherent in the coronavirus pandemic. At the end of the study, it is concluded that the State does not comply with the guarantee and protection of one of the fundamental rights of the working citizen: access to occupational health.
\end{abstract}

Keywords: Coronavírus pandemic; solid waste collectors; occupational health.

\footnotetext{
Artigo submetido em 16 de outubro de 2021 e aprovado em 04 de fevereiro de 2022.

* Estudante de Direito do Centro Universitário Barão de Mauá. E-mail: isabelabda@ hotmail.com
} 


\section{INTRODUÇÃO}

Com a promulgação da Constituição Federal de 1988, ainda que tardiamente, foi instituído o "Constitucionalismo Social", uma vez que o valor social do trabalho, a dignidade da pessoa humana, dentre outros direitos e garantias fundamentais passaram a constituir a base de todo o Estado. $\mathrm{O}$ trabalho, como um dos principais meios de ascensão da pessoa humana na sociedade, vez que é através dele que o indivíduo é integrado ou excluído do meio social, tornou-se palco da tutela Estatal, tendo em vista sua direta relação com a dignidade da pessoa humana. Responsável por exercer um papel de identificação social e ditar o quão valioso o cidadão é, ou não, trata-se de uma fonte de autorrealização ou, ainda, de amargura aos trabalhadores brasileiros.

A partir desta concepção, visto que aos 13 de março de 2020, por meio do Decreto Legislativo ${ }^{\circ} 006$, foi declarado estado de calamidade pública em decorrência da Pandemia do coronavírus, diversas medidas de segurança foram instituídas para preservação da saúde dos trabalhadores no ambiente de labor. Contudo, nesse cenário, importante indagar quais foram as medidas jurídico-protetivas aderidas com real aplicabilidade no meio ambiente de trabalho dos coletores de resíduos sólidos?

Em atenção à forma organizacional a qual os brasileiros são submetidos, os trabalhadores da limpeza urbana tornaram-se alvo de uma série de estigmas sociais e do fenômeno cuja nomenclatura foi determinada pelo psicólogo Fernando Braga da Costa, como "invisibilidade pública" (2004).

Este fenômeno social, em suma, é constituído pelo desaparecimento subjetivo de um grupo de indivíduos de características similarmente marginalizadas perante aos outros seres humanos.

Nesse contexto, o estudo realizado tem como objetivo analisar a (in)aplicabilidade das medidas jurídico-protetivas para enfrentamento da Pandemia do coronavírus no meio ambiente de trabalho da limpeza urbana. Ademais, busca observar como isso reflete a invisibilidade pública na qual esses indivíduos estão inseridos e o quão danoso e degradante essa submissão pode ser, especialmente em meio a um estado de calamidade pública como o atualmente enfrentado.

Para atingir tais objetivos, utilizou-se do método de abordagem dedutivo e como método de procedimento o de análise de caso. O objetivo é verificar se as medidas e os protocolos de segurança, a serem obrigatoriamente seguidos no meio ambiente de trabalho, teriam considerado, de fato, a realidade dos trabalhadores da limpeza urbana (garis), ou se, novamente, esse grupo social teria sido abarcado pelo esquecimento perante as políticas públicas.

Dessa forma, o trabalho em epígrafe foi estruturado em três tópicos. O primeiro irá observar quais foram as medidas adotadas para prevenção da COVID-19 nos ambientes de trabalho. Em seguida, analisar-se-ão as divergentes conceituações do que, verdadeiramente, constitui o local de trabalho de trabalho dos coletores de resíduos sólidos. Por fim, tendo evidenciado quais são os protocolos de segurança instituídos para seguimento (obrigatório) no ambiente de trabalho pelos empregadores e qual é o ambiente de trabalho dos coletores de resíduos sólidos, será analisado se o direito à saúde pelos trabalhadores tem sido devidamente assegurado pelo Estado em tempos de Pandemia. Nesse sentido, na próxima subseção serão evidenciadas quais foram as medidas estabelecidas para prevenção, controle e mitigação dos riscos de transmissão da covid-19 nos ambientes de trabalho e como essas medidas estão abarcadas pelo Texto Constitucional.

\section{AS MEDIDAS ESTABELECIDAS PARA PREVENÇÃO, CONTROLE E MITIGAÇÃO DOS RISCOS DE TRANSMISSÃO DA COVID-19 NOS AMBIENTES DE TRABALHO}


A Constituição de um Estado, conforme disposto por Rodrigo César Rebello Pinho (2020), equivale à lei fundamental de organização de um país, delimitando e estruturando seus respectivos poderes.

Com a promulgação da Constituição Federal Brasileira de 1988, foi instituído um Estado Democrático de Direito (art. $1^{\circ}$, caput), no qual a preservação da dignidade passou a atuar como base principiológica da atuação estatal nas relações jurídico-privadas (BRASIL, 1988). Nesse contexto, ao Estado passou a ser conferido, no âmbito dos seus três Poderes, o poder-dever de garantia e proteção à pessoa humana. Assim, todos os indivíduos submetidos à soberania nacional passam a gozar de direitos como o direito à saúde, à segurança, à educação (arts. $5^{\circ} \mathrm{e}$ $6^{\circ}$ ) e ao acesso a um ambiente ecologicamente equilibrado (arts. 23, VI e 225, caput) (BRASIL, 1988).

O Texto Constitucional ainda evidencia a inclusão do ambiente de trabalho como uma das subdivisões do meio ambiente em geral (art. 200, IV, BRASIL, 1988). O Supremo Tribunal Federal, em transcrição do parecer do Ministério Público Federal, reconheceu que "a existência digna (...) perpassa necessariamente pela defesa do meio ambiente (art. 170, IV, da CRFB/88), nele compreendido o meio ambiente laboral (art. 200, inciso VIII, da CRFB/88)". Diante disso, todas as leis e demais atos normativos referentes à preservação do meio ambiente em sua magnitude tornaram-se aplicáveis ao meio ambiente de trabalho. Consequentemente, converteu-se em dever jurídico e social, de todos os brasileiros, de preservação do equilíbrio (também) do ambiente de trabalho.

Ainda sob o aspecto da dignidade do trabalhador humano, a Constituição Federal de 1988, "também cuidou de regulamentar sobre a redução dos riscos iminentes ao trabalho (art. $7^{\circ}$, XXII) - necessidade não só do Estado, mas de todos os envolvidos - e redução de riscos de doenças e outros agravos ao trabalhador" (GARCIA, 2020, p. 12). Ademais, o legislador Constitucional, a fim de que se fizessem reduzidos os riscos inerentes ao trabalho, elaborou normas de preservação à saúde, à higiene e à segurança dos empregados. Ainda, em atenção às situações de risco a que os trabalhadores submetidos à realização de atividades penosas, insalubres e perigosas, foi assegurado o recebimento de um adicional de remuneração (GARCIA, 2020, p. 13).

Dessa forma, com a disseminação da COVID-19 no território nacional, aos 03 de março de 2020 foi reconhecido estado de calamidade púbica pelo Decreto Legislativo $\mathrm{n}^{\mathbf{0}} 006$ (BRASIL, 2020). Consequentemente, o meio trabalhista sofreu uma série de adaptações, principalmente perante as eventuais contaminações pelo COVID-19 no ambiente de trabalho.

O Direito do Trabalho, como fonte reguladora das relações de emprego e às que a elas se equiparem (LEITE, 2020), passou a visar a adoção de medidas de equilíbrio da função social do trabalho para/com a proteção da saúde do proletariado. Reconhecido pela Organização Mundial da Saúde - OMS que seria o distanciamento social a principal forma de combate ao contágio do vírus em evidência (ORGANIZAÇÃO MUNDIAL DA SAÚDE, 2020), o meio jurídico passa a regulamentar o seguimento das medidas de segurança recomendadas. No ambiente de labor, medidas de saúde, higiene e segurança passam a ser adotadas de forma excepcional e necessariamente severas.

Com o intuito de que a função social das relações de trabalho se mantivesse assegurada e em conformidade com a dignidade e saúde dos empregados, a adoção dos protocolos de segurança tornou-se fator condicionante para o funcionamento comercial. Em 18 de junho de 2020, passou a vigorar a Portaria Conjunta n. 20, responsável por dispor acerca das medidas a serem adotadas para prevenção, controle e mitigação dos riscos de transmissão da COVID-19 nos ambientes de trabalho (BRASIL, 2020). Tratar-se-á deste tema mais adiante.

No que tange à conceituação do meio ambiente de trabalho, faz-se oportuno esclarecer que ele vem sendo entendido tanto como um conjunto "de condições existentes num local de trabalho relativo à qualidade de vida do trabalhador" (ARAÚJO, 2021), quanto "de condições 
internas e externas do local de trabalho e sua relação com a saúde dos trabalhadores" (MACHADO, 2001). Em contrapartida, parte dos estudiosos defendem que o meio ambiente de trabalho ultrapassa qualquer construção teórica, visto que se trata de um direito fundamental do trabalhador constitucionalmente assegurado (MARANHÃO, 2017). Posto isso observa-se que, ainda que se façam presentes pontos de divergência, é pacífico o entendimento de que o meio ambiente de trabalho é direta e indiretamente relacionado com o poder-dever de preservação e tutela da saúde do trabalhador, em seus amplos aspectos.

Com o objetivo de garantia e proteção da dignidade da pessoa humana meio a fiscalização das condições sociais, econômicas e ambientais, nas quais os cidadãos trabalhadores estejam sendo submetidos (LEITE, 2020), o Direito do Trabalho exerce um papel de "garantidor Constitucional". Isso em atenção ao fato de que, com a instituição do sistema capitalista sob o qual a população brasileira se faz inserida, o ramo jurídico trabalhista surgiu com intuito de mediar a relação entre o capital e o trabalho (BRITO, 2021), garantindo-se assim as melhores condições possíveis aos trabalhadores.

Em outros termos, o Direito do Trabalho acaba por atuar direta e incisivamente sobre a falta de humanidade nas relações de emprego, muitas vezes guiadas exclusivamente pela "MaisValia". Para tanto, o meio jurídico em questão deve valer-se de valores e demandas que conversem com a mutável estruturação do meio social e as relações que do mesmo sejam derivadas, sempre em concordância com os ideais e princípios constitucionais.

Com a instauração da Pandemia do coronavírus tem-se constituído um cenário cujo meio econômico-social vem sendo ferozmente atingido. Os comerciantes/empresários que tinham o contato e exposição física como fatores primordiais para o funcionamento de seus respectivos estabelecimentos, motivados pela impossibilidade logística e/ou pela insuficiência de capital para uma "reestruturação à distância", obtiveram como única escolha: "fechar as portas" (PAMPLONA, 2020).

O desemprego e a impossibilidade de permanecer em casa para subsistência própria dos que são economicamente dependentes do mercado, levou grande parte dos brasileiros a infringir as recomendações da Organização Mundial da Saúde - OMS, e dos respectivos atos normativos delas derivados, permanecendo fisicamente no mercado de trabalho. Consequentemente, a adoção das medidas expostas na Portaria Conjunta n. 20 (BRASIL, 2020) traz consigo uma série de deveres cujo descumprimento ocasiona na responsabilização jurídica dos empregadores. Isso se evidencia mediante análise das decisões advindas do Supremo Tribunal Federal, o qual, a princípio, suspendeu ao artigo 29, da Medida Provisória 927/2020 (cuja vigência já fora encerrada), a fim de que a contaminação do empregado pela COVID-19 seja reconhecida como acidente de trabalho (BRASIL, 2020).

Embora a Constituição Federal do Brasil tenha a preservação da dignidade da pessoa humana como um de seus fundamentos, a seguir, far-se-á exposto um ambiente de trabalho inserido na contramão dos Direitos Fundamentais, especialmente em tempos de Pandemia: o meio ambiente de trabalho dos garis.

\section{O MEIO AMBIENTE DE TRABALHO DOS GARIS}

A estrutura basilar do meio ambiente de trabalho, em linhas gerais, é composta, essencialmente, por três elementos: o ambiente em si, a técnica e o homem. Essa tríade é associada a fatores de produção - mais detalhadamente tratados e abordados pela ciência e economia - utilizados para a produção de mercadorias e geração de serviços. Em outros termos, os insumos tidos como essenciais para execução da função social do trabalho, constitucionalmente assegurada (BRASIL, 1988), fazem-se direta e indiretamente relacionados à terra, ao capital e ao trabalho (MARANHÃO, 2016). 
A amplitude do termo "meio ambiente do trabalho" dificulta uma concreta e pacífica conceituação (SIQUEIRA, 2018). Contudo, isso não foi fator impeditivo para que a previsão normativa, tanto em âmbito constitucional quanto infraconstitucional, fosse realizada. Tal fator, intencionalmente, desencadeia o poder-dever de tutela do trabalhador pelo Estado, mediante fiscalização da observância das condições de trabalho a que ele vem a ser submetido (BRASIL, 1988 , art. $225, \mathrm{~V}, \S 1^{\circ}$ ).

O exercício da atividade dos garis, em específico, limita-se à coleta de lixo que, embora possua enorme relevância para a sociedade em geral, perante o meio social é vista como um trabalho de "menor importância". Nesse contexto, os cidadãos trabalhadores submetidos à realização desta atividade fazem-se submetidos a um fenômeno de desaparecimento psicossocial de, no caso em epígrafe, um grupo de sujeitos, perante os demais seres compositores da sociedade (LOPES, 2012).

Fomentada pelo sistema burguês-capitalista brasileiro, a busca incessante e socialmente inconsequente pelo lucro, em termos gerais, vem gerando de forma gradativa uma, cada vez maior, amargura entre os trabalhadores e cidadãos nacionais. As condições precárias e muitas vezes desumanas a que, em especial, os trabalhadores subalternos são submetidos, marcam a personalidade por palavras e imagens que, em suma, desumanizam suas respectivas percepções, fantasias, memórias e linguagens (COSTA, 2004). Traços de uma nítida dominação política, em meio à supervalorização do capital e uma evidente desvalorização e desrespeito ao trabalhador como pessoa humana.

Nesses termos, a fim de que o ambiente do trabalho dos garis seja juridicamente analisado, a conceituação deve ser realizada sob todos os seus aspectos que, segundo Ney Maranhão (2016), faz-se subdividida em três: o ambiental, o técnico e o homem. Isso em atenção ao fato de que o mesmo não é constituído apenas pelo cenário em que o labor é realizado, mas toda a dinâmica de interação dos múltiplos e complexos fatores sociais e naturais.

O elemento ambiental resume-se ao local onde ocorre a prestação de serviço, sendo ainda abarcado pelos itens móveis, imóveis, naturais e os humanamente construídos. "Trata-se, em suma, do específico cenário fenomênico diante do qual se executa algum trabalho" (MARANHÃO, 2016). A técnica, em resumo, trata-se da adoção de "modos de execução" de um determinado exercício laboral, a fim de que o resultado para o qual o trabalhador foi contratado, venha a ser executado. Por fim, o último elemento, o homem, constitui a figura central dessa estrutura relacional produtiva. Contudo, cumpre esclarecer que a simples presença do ser humano não possui condão de revelar uma condição ambiental (MARANHÃO, 2016).

Nesse sentido, o meio ambiente de trabalho dos garis que trabalham diretamente com a coleta de lixo domiciliar e hospitalar (em caminhões), para ser evidenciado, deve ser analisado sob todos os aspectos supra. Constitui o aspecto ambiental a oscilação entre a rua e o caminhão; já o aspecto técnico trata-se da coleta manual dos enormes e pesados sacos de lixo e o elemento homem constitui-se no gari, como pessoa humana. Em outros termos, o meio é formado pela dinâmica estabelecida entre os garis, a rua, o caminhão e o lixo para a limpeza das cidades e, consequentemente, para manutenção do meio urbano em uma condição ecologicamente equilibrada.

Porém, não basta conhecer os elementos responsáveis por constituir o meio ambiente de trabalho dos garis para ser obtida uma verdadeira compreensão jurídica e social do que, de fato, o constitui. "Cumpre também assimilar as realidades que, jurídica e dinamicamente, são formadas a partir desses elementos, resultando nos fatores de risco passíveis de existência no labor-ambiente" (MARANHÃO, 2016). Nesse diapasão, evidencia-se que são diversos os vetores axiológicos atuantes na mesma base fática que permitem a extração de diversas normas e entendimentos advindos de um único texto (BALLAN JUNIOR, 2018, p. 278). Assim, para que uma verdadeira compreensão seja obtida sobre a dinâmica que, de fato, abarca o dia a dia 
de trabalho dos trabalhadores em estudo, fatores psicológicos, políticos e sociais devem ser verdadeiramente compreendidos.

Fernando Braga da Costa (2004) dispõe acerca do fenômeno da invisibilidade púbica constituído sobre grupos sociais como o dos Coletores de Lixo Urbano, que intersubjetivamente desaparecem meio aos outros homens. Este fenômeno decai majoritariamente sobre as profissões das classes mais pobres cujos trabalhos realizados são simplificados. Isso porque apesar de a execução do trabalho ser simplificada, a mesma submete-se a uma organização de trabalho complexa e responsável por isolar em um canto o comando puro; "noutro, a mais pura subordinação" (COSTA, 2004).

É necessário ressaltar que os garis, independente da categoria em que estejam inseridos, pelos motivos já expostos, são vítimas rotineiras da invisibilidade pública, ocasionada pelo exercício da sua profissão. Fato que contradiz o que de fato deveria se tratar por função social do trabalho, constitucionalmente prevista (BRASIL, CBRF/1988). Isso porque não só a função em retro como em consideração a todo englobado pelo Estado de Direito nos termos da Constituição Federal vigente, e, ainda pela Consolidação das Leis do Trabalho - CLT, deveria ser assegurada a igualdade/isonomia entre os cidadãos brasileiros conjuntamente ao acesso à uma vida digna.

Em sentido amplo, a jurisdição constitucional brasileira envolve a interpretação e a aplicação da Constituição do Estado, a qual tem sido ampliada após a Emenda Constitucional $\mathrm{n}^{\mathrm{o}}$ 16/65 (controle principal e concentrado), expandindo-se verdadeiramente a partir da Constituição Federal de 1988 (BARROSO, s/d, p. 9).

Dessa forma, em análise ao ambiente de trabalho dos garis, percebe-se um sentido negativo do trabalho, diferindo-o do sentido de "labor", visto que não possibilita a construção de uma identidade e de autorrealização própria e perante a sociedade (LOPES, 2012). É justamente a execução do trabalho em questão que torna o indivíduo socialmente invisível e o reduz ao objeto da atividade laboral exercida: o lixo. Tal fator ilustra a realidade dos coletores de lixo urbano e as peculiaridades inerentes à atividade exercida, a qual deve ser efetivamente abarcada pelo Princípio constitucional da Isonomia (BRASIL, 1988, art. 5, caput).

Nesse sentido, em 13 de março de 2020, ao ser reconhecido o estado de calamidade pública pelo coronavírus (BRASIL, 2020), os cidadãos trabalhadores já invisibilizados pelo meio social foram novamente esquecidos, conforme será exposto a seguir.

\section{A (IN)APLICABILIDADE DAS MEDIDAS DE PREVENÇÃO E MITIGAÇÃO DOS RISCOS DE CONTÁGIO DA COVID-19}

O trabalho, enquanto labor, constitui uma das principais atividades desenvolvidas para a satisfação e ascensão do ser humano, visto que proporciona a manutenção das relações interpessoais, a sobrevivência e a autorrealização do indivíduo (VASCONSELOS, 2020). Porém, quando as demandas para a amenização da insalubridade ou periculosidade inerentes à realização da atividade laboral não são adequadamente fornecidas, o que deveria constituir uma oportunidade para os cidadãos obterem, dentre outras coisas, uma saúde melhor, torna-se uma fonte de doenças funcionais.

Aos 18 de junho de 1978 é publicada a Portaria 3.214, do Ministério do Trabalho, sob a qual foram aprovadas Normas Regulamentadoras com o intuito de resguarde e tutela da saúde e segurança do trabalhador (BRASIL, 1978). "O seu cumprimento é obrigatório pelas empresas privadas e públicas, órgãos públicos da Administração Direta e Indireta, assim como o Poder Legislativo e Judiciário que tenham empregados regidos pelo regime celetista" (RIBEIRO, 2020).

A Norma Regulamentadora 24, instituída meio a Portaria retro, é responsável pela previsão das condições mínimas de conforto e higiene a serem observadas pelos órgãos supra. 
A título de exemplo, meio ao Anexo II, dispõe sobre as condições sanitárias e de conforto aplicáveis aos trabalhadores em trabalho externo de prestação de serviço, sob o qual, são excetuados profissionais como entregadores, vendedores, carteiros e similares, dentre eles, os Garis (BRASIL, 1978).

Com a Conferência Geral da Organização Internacional do Trabalho convocada em Genebra pelo Conselho de Administração do Departamento Internacional do trabalho, após ter decidido pela adoção de inúmeras propostas relativas à segurança, higiene e ao meio ambiente de trabalho, optou pela adoção do Convênio sobre segurança e medicina dos trabalhadores de 1981. Nesse contexto, com a vigência da denominada "Constituição Cidadã", passou a ser constitucionalmente assegurado aos trabalhadores o direito "a redução dos riscos inerentes ao trabalho, por meio de normas de saúde, higiene e segurança" (BRASIL, 1988, art. $7^{\circ}$, inciso XXII). À vista disso, a CLT passa a dispor em seu Capítulo V (art. 154 e seguintes), acerca da Segurança e Medicina do Trabalho (RIBEIRO, 2020).

Observadas todas as ideias até aqui expostos acerca da invisibilidade pública e sua direta relação para com os trabalhos subalternos, pode-se citar este regulamento como um exemplo deste pensamento excludente e discriminador. Os executores dos trabalhos simplificados supracitados são excluídos até da regulamentação que, a princípio, foi instituída com o objetivo de tornar o local de trabalho mais digno. Como se não tivessem os mesmos direitos constitucionalmente instituídos e, teoricamente, guiados sob o aspecto da igualdade, são esquecidos.

Regulamentados pela NR 21, que versa sobre Trabalhos a Céu Aberto, aos garis e os demais profissionais "excetuados" das normas sanitárias de higiene são asseguradas condições "compatíveis com o gênero de atividade" (BRASIL, 1978). Rebaixados e reduzidos ao objeto do trabalho exercido, não gozam de qualquer previsão que realmente exerça função de tutela pela dignidade enquanto cidadão e trabalhador. Os riscos à saúde pública inerentes ao contato para/com os resíduos sólidos decorrem da interação de um conjunto de fatores sociais, ambientais, ocupacionais, de consumo, dentre outros padrões de desenvolvimento adotados. Estes, em resumo, "vem implicando na deterioração da qualidade de vida nos grandes centros urbanos" (SIQUEIRA, 2008).

Assim, faz-se mensurado o poder de deterioração do trabalho exercido pelos garis que lidam diretamente com esses resíduos em prol da saúde dos demais cidadãos. Prova disso é o fato de que, por meio de um estudo realizado por Dall'Agnol e Fernandes, em 2007, foi evidenciado que as mais frequentes morbidades derivam do contato dos seres humanos com os resíduos sólidos e recicláveis, sendo "as doenças diarreicas, diretamente relacionadas à lavagem das mãos, e aquelas transmitidas por vetores biológicos e mecânicos" (VASCONCELOS, 2020, p. 367).

Com a Pandemia do coronavírus, pelo todo evidenciado e, principalmente, pelo poderdever dos órgãos públicos e privados, bem como do Estado, de criar normas regulamentadoras que viessem a reduzir os riscos agora em evidência, também no ambiente de trabalho foi elaborada a ainda vigente Portaria Conjunta n. 20 (BRASIL, 2020). Em linhas gerais, ela determina a obrigatoriedade da organização em informar e fornecer recursos para a frequente higienização das mãos próximos aos locais de trabalho e, ainda, disponibilizar máscaras cirúrgicas ou de tecido, dentre outras medidas de higiene, saúde e segurança do trabalhador.

Dessa forma, visto que os garis são cidadãos trabalhadores e todos esses têm direito a trabalhar em segurança em tempos de Pandemia do coronavírus, deveria aos garis ser assegurado igual direito. Para tanto, observadas as peculiaridades do meio ambiente de trabalho dos coletores de resíduos sólidos (a ponto de nem mesmo a NR 24 ser a eles aplicável), o requerimento de adoção das mesmas medidas de segurança para garantia da saúde desses trabalhadores constitui tutela fantasiosa. 
Isso porque é nítida a impossibilidade logística de os caminhões, compositores do local de trabalho dos indivíduos em questão, venham a fornecer a frequente higienização das mãos, vez que estão ocupadas poupando os trabalhadores, entre uma rua e outra, de uma degradação física ainda maior. Prova disso é o fato de que, conforme o estudo realizado por Dall'Agnol e Fernandes (VASCONSELOS, 2020), em tempos não pandêmicos, as doenças ocupacionais a que os trabalhadores de limpeza urbana são submetidos têm como fator desencadeador a impossibilidade de higienização das mãos.

As máscaras condizentes com o salário recebido (as de pano), ao se depararem com o calor não só externo, mas biologicamente produzido pelo corpo dos coletores, tendo em vista as exaustivas horas correndo e arremessando sacos pesados de lixo, rapidamente estão enxarcadas de suor, tornam-se ineficientes. O contato direto com resíduos muitas vezes infectados pelo da COVID-19, em meio aos sacos de lixos de moradores infectados e, ainda, hospitalares, nada mais constitui que o inevitável, a contaminação, e o mesmo se repete quanto a recomendação de não levar as mãos ao rosto.

Marcados pelo já mencionado fenômeno da invisibilidade pública, desde antes dos tempos de Pandemia os garis estavam fadados ao esquecimento. Expectativa que, inquestionável e tragicamente fora suprida pela perversa organização política, social e econômica a que são submetidos. Aos empregados e empregadores instituiu-se o dever de higienizar as mãos frequentemente, respeitar o distanciamento de, no mínimo, um metro, manter-se com máscaras limpas e secas e preservar um meio ambiente de trabalho higiênico. Contudo, foram esquecidos os trabalhadores cujo local de trabalho é a rua, assim como os caminhões, que lidam direta e inevitavelmente com o lixo, muitas vezes contaminado pelo vírus e que, durante a maior parte da carga horária, mantêm-se correndo, escorrendo suor e pendurados sobre um veículo em movimento.

\section{CONCLUSÃO}

A Constituição Federal de 1988, desde a sua promulgação, exerce um papel basilar na estruturação e manutenção do Brasil como Estado Democrático de Direito, vez que garante a tutela da pessoa humana meio a asseguração de seus Direitos Fundamentais. Dentre os direitos e deveres constitucionalmente previstos, como fator inerente ao papel da Constituição de 1988 está a dignidade dos cidadãos, em especial, a do cidadão trabalhador. Isso porque, meio a uma sociedade política e economicamente estruturada sob os moldes capitalistas, a subsistência e a autorrealização dos indivíduos, em linhas gerais, deriva quase que exclusivamente do trabalho enquanto labor.

Nesse contexto, constata-se que o exercício laboral se trata de uma das principais fontes de ascensão do ser humano perante à sociedade. Dessa forma, em atenção aos princípios e direitos constitucionais assegurados, deve ao trabalhador ser assegurado um meio ambiente de trabalho ecologicamente equilibrado, conforme infere-se nos artigos 23, inciso VI e 225, caput, ambos do Texto Constitucional.

Contudo, para fins de um melhor e mais eficiente resguardo do meio ambiente de trabalho pelo Estado e demais responsáveis (empregadores e/ou os que eles, representem), é indispensável que seja certificado o verdadeiro entendimento sobre o que, de fato, o constitui. Diante dessa demanda, foi observado que o meio ambiente de trabalho, em regra, apesar de ultrapassar qualquer construção teórica, faz-se diretamente relacionado com a saúde e a qualidade de vida do trabalhador e, consequentemente, abarca as condições dentro e fora do local de trabalho. Ligado de forma intrínseca com a dignidade do trabalhador como pessoa humana e de direito, a preservação de seu equilíbrio constitui poder-dever do Estado e demais órgãos públicos, diretos e/ou indiretos. 
Preservar o meio ambiente de trabalho é cuidar e fazer valer a supremacia constitucional. Contudo, ainda em atenção à desigualdade política, social e econômica da qual o Brasil é refém, existem grupos que, uma vez resumidos ao objeto de trabalho e não tidos como pessoas humanas e, com isso, portadora de tantos direitos quanto qualquer outro melhor estabelecido socialmente, são esquecidos e postos uma linha abaixo da prioridade. Também conhecidos como trabalhadores subalternos, são assim denominados os indivíduos que realizam trabalhos "simplificados", cuja mão-de-obra pode ser facilmente substituída e, por isso, acabam não sendo igualmente protegidos e preservados como de direito. Enfatizam-se, dentre as diversas subdivisões profissionais desse grupo, os garis.

Diante desse cenário de invisibilidade e esquecimento, desde muito antes constituído e consolidado às vias cruéis do capitalismo, com a chegada do coronavírus no Brasil, cujos impactos à saúde eram até então desconhecidos, aos 13 de março de 2020, foi reconhecido o Estado de Calamidade Pública. Nesse sentido, com o parecer da Organização Mundial da Saúde - OMS, de que o distanciamento social constituiria a principal forma de contenção da COVID19, foram instituídas em todo o país medidas jurídicas, políticas e administrativas nessa mesma perspectiva. Consequentemente, foi determinado que os empresários/comerciantes se adaptassem a tal realidade meio a instituição de teletrabalho e de "delivery", a fim de que fosse preservada a saúde deles, dos funcionários e dos consumidores do produto ofertado.

Com as dificuldades de reestruturação "a distância" e/ou, ainda, a inviabilidade logística dos que detinham o contato direto com o público como fator primordial de funcionamento, muitos dos comerciantes optaram por fechar as lojas. Em contrapartida, os que continuaram com os seus respectivos estabelecimentos, como fator condicionante de funcionamento tiveram que se adaptar perante a nova realidade, a fim de que o meio ambiente de trabalho se mantivesse seguro para o exercício laboral e, com isso, fosse preservada a saúde e dignidade dos trabalhadores. Dessa forma, aos 18 de junho de 2020, passou a vigorar a Portaria Conjunta n. 20, que estabeleceu uma série de protocolos de segurança a serem, obrigatoriamente, adotados nos ambientes de trabalho.

Contudo, embora estabelecidas as medidas de segurança, uma parcela do grupo social anteriormente mencionado (dos trabalhadores subalternos), mais especificamente os garis, que trabalham com a coleta de lixo domiciliar e hospitalar em caminhões, foi novamente esquecida. Para tal constatação, foi meio a utilização do método dedutivo, realizada a ilustração de qual seria o meio ambiente de trabalho dos Garis. Nesse sentido, foi observado que o local de trabalho dos profissionais em questão é formado pela dinâmica estabelecida entre os garis, a rua, o caminhão e os sacos de lixo.

Diante das análises das condições do local de trabalho e a NR 21, que em termos gerais, regulamenta aos trabalhos em céu aberto, foi observado que entre a dinâmica caminhão-rua intermediada por corridas com o peso dos sacos de lixo, o protocolo de segurança estabelecido, logisticamente, não conseguiria ser cumprido. Logo, dada a importância e "indispensabilidade" do seguimento das exigências sanitárias estabelecidas meio a Portaria Conjunta mencionada, a impossibilidade de adoção dessas medidas de segurança no exercício do trabalho, acarreta a total desproteção, desamparo e, desrespeito à dignidade desses cidadãos trabalhadores e, consequentemente, uma falha estatal que deve o quanto antes ser solucionada.

\section{REFERÊNCIAS}

BARROSO, Luís Roberto. Neoconstitucionalismo e constitucionalização do direito $(\mathrm{O}$ triunfo tardio do direito constitucional no Brasil). Disponível em:

https://luisrobertobarroso.com.br/wp- 
content/uploads/2017/09/neoconstitucionalismo_e_constitucionalizacao_do_direito_pt.pdf. Acesso em: 18 jul. 2021.

BRASIL. Portaria no 3.214, de 08 de junho de 1978. Aprova as Normas Regulamentadoras NR - do Capítulo V, Título II, da Consolidação das Leis do Trabalho, relativas a Segurança e Medicina do Trabalho. Disponível em: portaria_3-214_aprova_as_nrs.pdf (www.gov.br). Acesso em: 21 jul. 2021.

BRASIL. Constituição da República Federativa do Brasil de 05 de outubro 1988. Disponível em: Constituição (planalto.gov.br). Acesso em 12 jul. 2021.

BRASIL. Decreto Legislativo 006 de 2020. Reconhece, para os fins do art. 65 da Lei Complementar $\mathrm{n}^{\circ} 101$, de 4 de maio de 2000, a ocorrência do estado de calamidade pública, nos termos da solicitação do Presidente da República encaminhada por meio da Mensagem $\mathrm{n}^{\circ}$ 93, de 18 de março de 2020. Disponível em: DLG6-2020 (planalto.gov.br). Acesso em: 12 jul. 2021.

BRASIL. Medida Provisória n 927, de 22 de março de 2020. Dispõe sobre as medidas trabalhistas para enfrentamento do estado de calamidade pública reconhecido pelo Decreto Legislativo $\mathrm{n}^{\circ}$ 6, de 20 de março de 2020, e da emergência de saúde pública de importância internacional decorrente do coronavírus (covid-19), e dá outras providências. Disponível em: http://www.planalto.gov.br/ccivil_03/_Ato2019-2022/2020/Mpv/mpv927.htm. Acesso em: 13 jul. 2021.

BRASIL. Portaria Conjunta no 20, de 18 de junho de 2020. Estabelece as medidas a serem observadas visando à prevenção, controle e mitigação dos riscos de transmissão da COVID19 nos ambientes de trabalho (orientações gerais) (Processo $\mathrm{n}^{\circ} 19966.100581 / 2020-51$ ). Diário Oficial da União. Edição 116, seção 1, p. 14. Disponível em: covid_19_-_sit__orientacoes_gerais.pdf (www.gov.br). Acesso em: 06 jul. 2021.

BRASIL. Superior Tribunal Federal. Ação Direta de Inconstitucionalidade: 6377/DF, 0089879-31.2020.1.00.0000. DECISÃO AÇÃO DIRETA DE INCONSTITUCIONALIDADE - OBJETO - PERDA. [...] 2. Considerado o término, em 19 de julho de 2020, do prazo de vigência da Medida Provisória $n^{\circ}$ 927/2020 [...] (STF - ADI: 6377 DF 0089879-31.2020.1.00.0000, Relator: MARCO AURÉLIO, [...]). MARCO AURÉLIO. Data de Julgamento: 12/08/2020. Data de Publicação: 20/08/2020.

BRASIL. Supremo Tribunal Federal. Agravo em Recurso Extraordinário. ARE 664335/SC. Acórdão. LUIZ FUX. Data de Julgamento: 14 jul. 2012. Data de Publicação: 07 jul. 2013. Disponível em: https://jurisprudencia.stf.jus.br/pages/search?classeNumeroIncidente=ARE\%20664335\&base $=$ acordaos $\&$ sinonimo $=$ true $\&$ plural $=$ true $\&$ page $=1 \&$ pageSize $=10 \&$ sort $=\_$score $\&$ sortBy $=$ desc $\&$ isAdvanced=true.

BRITO, Rose Dayanne Santos. Direito do trabalho na contramão: a precarização como regra. Revista Katál, Florianópolis, v. 24, n. 1, p. 223. jan/abr. 2021.

COSTA, Fernando Braga da. Homens invisíveis: relatos de uma humilhação social. Ed. Globo. São Paulo. 2004. 
GARCIA, Andréa das Graças Souza Camacho Gimenez; GARCIA, Glauber Camacho Gimenez; CONTE, Rayssa. O pedido cumulado de adicional de insalubridade, periculosidade, penosidade à luz do princípio da dignidade da pessoa humana. Revista Eletrônica da Faculdade de Direito de Franca, v. 15, n. 2, p. 11-37, 2020.

BALLAN JUNIOR, Octahydes. Teoria tridimensional do Direito de Miguel Reale nas decisões dos tribunais superiores. Revista Pensamento Jurídico, São Paulo, v. 12, n. 2. 2018.

LEITE, Carlos Henrique Bezerra. Curso de Direito do Trabalho. São Paulo: Saraiva, 2020.

LOPES, Fernanda Tabaral; MACIEL, Ana Alice Duarte; CARRIERI, Alexandre de Pádua; DIAS, Derli de Souza; MURTA, Ivana Benevides Dutra. O significado do trabalho para os garis: um estudo sobre representações sociais. Perspectivas em Políticas Públicas, Belo Horizonte. v. 5, n. 10, 2012.

MARANHÃO, Ney. Poluição Labor-Ambiental. Revista Nova Hileia. v. 2, n. 2, 2017. Disponível em: http://periodicos.uea.edu.br/index.php/novahileia/article/view/1238/782. Acesso em: 19 jul. 2021.

MARANHÃO, Ney. MEIO AMBIENTE DO TRABALHO: conceito jurídico-conceitual. Revista Meio ambiente do trabalho direitos, trabalho e política social. Cuiabá. v. 2, n. 3. 2016.

NASCIMENTO, Sônia Maria Rodrigues; ARAÚJO, Gizelda Rodrigues. Medidas protetivas e de segurança do meio ambiente de trabalho e o enfrentamento da Covid-19. Revista Ibero Americana de Humanidades, Ciências e Educação - REASE, v. 7. n. 6. jun. 2021, p. 174.

ORGANIZAÇÃO MUNDIAL DA SAÚDE (OMS). OMS diz que máscaras cirúrgicas sozinhas não bastam para proteger da Covid-19. ONU News | Perspectiva Global Reportagens Humanas. Disponível em: OMS diz que máscaras cirúrgicas sozinhas não bastam para proteger da Covid-19 | ONU News. Acesso em: 21 jul. 2021.

PAMPLONA, Nicola. 522 mil empresas fecharam as portas por pandemia, diz IBGE. Folha de S. Paulo. Rio de Janeiro. Disponível em: 522 mil empresas fecharam as portas por pandemia, diz IBGE - 16/07/2020 - Mercado - Folha (uol.com.br). Acesso em: 21 jul, 2021.

PINHO, Rodrigo César Rebello. Direito constitucional: teoria geral da constituição e direitos fundamentais. Saraiva Educação. v. 17. 18. ed. São Paulo. 2020.

SIQUEIRA, Mônica Maria; MORAES, Maria Silvia. Saúde coletiva, resíduos sólidos urbanos e os catadores de lixo. Artigo Article. 2008. Disponível em: https://www.scielo.br/j/csc/a/n5GCwf9wtQccdjQR3HwZqJg/. Acesso em: 18 jul. 2021.

SIQUEIRA, Vitor da Costa Honorato; FRANCISCHETTO, Gisellene Passon Picoretti. Direito fundamental ao meio ambiente do trabalho digno: medidas de desinvibilização do trabalhador. Revista Internacional de Direito Ambiental e Políticas Públicas. Macapá, n. 10. 2018. 
VASCONCELOS, Joaquim Pedro Ribeiro; GUIMARÃES, Sílvia Maria Ferreira; ZANETI, Izabel Cristina Bruno Bacellar. Condições de trabalho e saúde de uma associação de catadores de materiais recicláveis de Ceilândia, Brasil. Jangwa Pana, vol. 19, n. 3. 2020. DOI: https://doi.org/10.216/issn.1657-4923. Acesso em: 19 jul. 2021.

ZARELLI, Renata Calheiros; RIBEIRO, Luiz Alberto Pereira. Reforma trabalhista: da possibilidade de retrocesso da garantia ao meio ambiente do trabalho nos contratos intermitentes. Revista de Direito do Trabalho, vol. 212, p. 275-293, 2020. 